\title{
Effect Physical Activity and Nutrition During The Covid-19 Pandemic
}

\author{
I Gede Dharma Utamayasa \\ Department of Physical Education, PGRI Adi Buana Surabaya University, Indonesia \\ *Corresponding author e-mail: dharmautamayasa@unipasby.ac.id
}

\begin{abstract}
The main key in fighting the corona virus is to always maintain endurance and be balanced with maximum nutritional intake. With regular nutritional intake and exercise, immunity will be maintained so that children who are able to ward off disease, if already healing will be faster. Nutritional problems that occurred during the pandemic resulted from changes in adolescent habits, especially in physical activity. This study aims to prove the relationship between physical activity and nutritional status in elementary school children N 1 Kaliuntu. This type of research is a survey. The target population is primary school children aged 7-9 years which means 30 students. The first data during the pandemic was 33\% and the proportion of the nutritional status of very thin, thin, obese and obese elementary school students was $29.9 \%$. The second data shows that there is a relationship between physical activity during the Covid-19 pandemic and the nutritional status of elementary school children at primary school N 1 Kaliuntu.
\end{abstract}

Keywords: Physical activity, nutrition, the Covid-19 pandemic.

\section{Introduction}

The corona virus pandemic has not ended in Indonesia, every day the number of sufferers is still increasing. The corona virus does not really attack anyone, from children to the elderly. It is a viral disease that affects people's health and quality of life, causing respiratory infections such as mild and moderate pneumonia [1]. The main key in fighting the corona virus is to always maintain endurance and be balanced with maximum nutritional intake. The corona virus pandemic has caused many changes in everyday life. Maintaining a healthy diet is very important during this pandemic to maintain a good body. Now we need to be able to avoid exposure to the coronavirus and keep our healthy storage system healthy and in shape. Currently, there are not many specific studies related to the role of nutrition and physical activity to anticipate Covid-19. This becomes a challenge. Therefore, the responsibility of the individuals during the covid-19 pandemic lies in making an effort to choose a healthy life style, eat diets high in fruits and vegetables, exercise during free time, try to maintain a healthy weight, and get an adequate amount of sleep [2]. However, the interesting thing is that people who are not contagious are a population that is susceptible to Covid-19.

A lifestyle that is getting worse, such as frequent smoking, lack of or never doing physical activity, drinking large amounts of alcohol, and high obesity can contract Covid-19. To prevent the spread of this virus, it must be accompanied by a strong body immunity, of course, by improving life patterns, regular exercise and balanced nutrition. A good practice is to start exercising at lower intensities and durations and build up slowly [3]. In the midst of PSBB and physical distancing, experts reminded them to maintain nutritional and immune conditions, especially in children, because children do have a minimal prevalence of being infected with Covid-19. With regular nutritional intake and exercise, immunity will be maintained so that children are able to ward off disease, if healing will be faster. One of these immunity is by having a good and healthy diet to maintain body fitness so that it can increase body immunity. Lack of physical activity can increase the risk of obesity and obesity. More nutrition can cause disturbances in body functions such as heart disease, cancer and can shorten life. Conversely, activities that are not balanced with appropriate intake can lead to thinness or weight loss. Baseline data from the 2017 UNICEF survey proved that there were findings of changes in diet and physical activity in adolescents.

In the of pandemic, when the whole world is affected from the disease, nutrition is should be at our highest priority, especially when are dealing with a novel virus because here our immune system is the only barrier to deal with this novel coronavirus 19 [4]. The Covid-19 pandemic is currently epidemic, increasing the chances of teenagers not doing physical activity because they spend most of the time doing assignments from school online. Nutritional problems that occur during a pandemic result from changes in adolescent habits, especially in physical activity. The proportion of the Indonesian population according to the energy sufficiency level in 2014 in the age group 13-18 years is very low $52.5 \%, 30.3 \%$ less, $12.2 \%$ normal, and more than $5.0 \%$ while according to female sex is very low $46,7 \%$, less $33.4 \%$, 
normal $14.1 \%$ and more $5.8 \%$ (Kemenkes RI, 2016b). If fact, until now, the authors did not find research regarding the effect of nutritional habits on the severity or duration of covid-19 [5]. This study aims to prove the relationship between physical activity and nutritional status in elementary school children N 1 Kaliuntu.

\section{Literature Review}

To protect themselves from exposure to the corona virus, the world community has taken many major preventive measures. The Indonesian government has also implemented this policy in preventing Covid-19. Maintaining a diet with a balanced nutritional intake and regular physical activity is important in an effort to maintain endurance in the midst of a pandemic. Some research suggested the efficacy of vitamin supplements to prevent covid-19 in fections [6]. During a pandemic, it is increasingly important to maintain and improve the immune system to deal with the threat of the corona virus.

Stress reduction is important to maintaining a healthy immune system [7]. The immune system can be influenced by a person's lifestyle so that adopting a lifestyle is very important to maintain body immunity. During an outbreak, a good nutrition and a healthy lifestyle is extremely important [8]. If someone adopts an unhealthy lifestyle, the body becomes susceptible to various diseases due to decreased body immunity.

Measuring healthy immunity or not is certainly difficult to do, the important thing is that we must avoid exposure to the virus and keep the body's immunity healthy and fit. During a pandemic like this one thing that must be maintained is good physical activity, sleep patterns, diet and stress management. A person who has a viral infection will experience a decrease in appetite so that the amount and nutrients that enter the body decreases. A person who is malnourished will have the risk of contracting infection because the immune system decreases. Nutritional deficiencies, thus, are associated with an impaired immune system and render the body susceptible to various infections [9].

The first principle of consuming diverse foods means that the more diverse types of food consumed, the easier it is to fulfill nutrition. Specifically, the covid-19 control measures and travel restrictions may compromise the ability to maintain physical activity and healthy life styles including reduced consumption of diverse and nutritious diets [10]. In fact, the more varied the food is consumed, the easier it is for the body to obtain various substances that are beneficial to health. The second principle is to familiarize yourself with clean living habits, to get used to clean living habits will avoid sources of infection, Covid-19 always wash hands with soap and clean water, always wear a mask and nose when sneezing. The third principle of doing physical activity includes all kinds of body activities, one of which is an effort to balance the expenditure and intake of energy sources in the body. Although exercise training plays a vital role in preventing infection subsequent to the initial infection, the physiological response of the immune system is not completely known [11]. For schoolage children and adolescents (5-17 years). The recommendations are to participate in at least 60 min moderate-intensity to vigorousintensity physical activity, engage in no more than $2 \mathrm{~h}$ sedentary recreational screen time [12].

\section{Method}

This type of research is a survey. The target population is primary school children aged 7-9 years which means 30 students. The online survey was conducted boldly with google form media. Google media Useful form for quick questionnaires and via a link that is shared with primary school N 1 Kaliuntu. Descriptive analysis was carried out by categorizing the data to describe the distribution of variables. Bivariate analysis to determine the relationship between sample characteristics and nutritional status and the independent variables used paired sample t test.

\section{Results and Discussion}

Following is the distribution of physical activity and nutritional status

Table 1. Distribution of physical activity and nutritional status

\begin{tabular}{lll}
\hline $\begin{array}{l}\text { Variable } \\
\text { Physical Activity During a Pandemic }\end{array}$ & Frequency & Percentage \\
\hline Yes & 20 & 66,6 \\
No & 10 & 33,3 \\
Nutritional status & & \\
Very thin & 5 & 16,6 \\
thin & 4 & 13,3 \\
Normal & 15 & 50 \\
Fat & 3 & 10 \\
Obese & 3 & 10 \\
\hline
\end{tabular}

The distribution of physical activity in table 1 above shows that physical activity that was not carried out during the pandemic was $33 \%$ and the percentage of nutritional status was very thin, thin, obese and obese in primary school students was $29.9 \%$.

Table 2. Paired Sample T Tes.

\begin{tabular}{|c|c|c|c|c|c|c|c|c|}
\hline & \multicolumn{5}{|c|}{ Paired Differences } & \multirow[t]{3}{*}{$\mathrm{t}$} & \multirow[t]{3}{*}{ df } & \multirow[t]{3}{*}{ Sig. (2-tailed) } \\
\hline & \multirow[t]{2}{*}{ Mean } & \multirow[t]{2}{*}{ Std. Deviation } & \multirow[t]{2}{*}{$\begin{array}{l}\text { Std. } \\
\text { Error } \\
\text { Mean }\end{array}$} & \multicolumn{2}{|c|}{$\begin{array}{l}\text { 95\% Confidence } \\
\text { Interval of the } \\
\text { Difference }\end{array}$} & & & \\
\hline & & & & Lower & Upper & & & \\
\hline $\begin{array}{l}\text { Physical } \\
\text { activity - } \\
\text { nutritional }\end{array}$ & .56667 & 1.40647 & .25679 & .04148 & 1.09185 & 2.207 & 29 & .005 \\
\hline
\end{tabular}


Data table 2 above shows that there is a relationship between physical activity during the Covid-19 pandemic and nutritional status in elementary school children at primary school N 1 Kaliuntu.

Covid-19 world pandemic imposed a new set of challenges for the individual to maintain a healthy diet [2]. The nutritional status of primary school children is very important during the Covid-19 pandemic. During periods of isolation, all socioeconomic groups, ethnicities, and ages should maintain good helath by following the WHO PA recommendations of 150 minutes of moderate-intensity or 75 minutes of vigorous-intensity PA per week, or a combination of both [3].

Physical activity that did not do physical activity during the pandemic was $33.3 \%$ and the percentage of very thin, thin, obese and obese nutritional status among primary school students was $29.9 \%$. Physical activity carried out by primary school children during the Covid-19 pandemic was different from that before the pandemic. Extracurricular activities at school or sports are not practiced during a pandemic. The relationship between physical activity and nutritional status is sig 0.05 , which means that there is a significant effect during the Covid19 pandemic in primary schools at 1 time. Physical activity during the Covid-19 pandemic can prevent bad health conditions and the importance of physical activity during a pandemic is also related to the immune system (Rukmana et al., 2020). The condition of the Covid19 pandemic is a challenge for all of us to maintain a healthy physical and quality of life. Therefore, the practice of regular physical activity is invaluable to maintain good physical and mental health when facing the current challenges imposed by covid-19 [13].

Consumption of foods with balanced nutrition and vitamins is one of the keys to avoid contracting the virus that causes Covid-19. Vitamin $\mathrm{C}$, vitamin D and zinc have immune improving and immune regulating and assume synergistic role in supporting parts of both innate and adaptive immunity which contain epithelial obstructions, cell resistance and antibodies comprising the three primary lines of resistant protection [4]. A good immune system or immune system is the most optimal protection. During the Covid-19 pandemic, immunity is a major priority that needs to be improved to fight viruses and bacteria in the body. Consequently, although further work needs to be done on the relationship between the usual dietary pattem of covid-19 patients with the severity and duration of the disease, according to results of the presents study, healthy nutrition such as further consumption of fruits can be recommended to prevent the servere from of covid-19 [5].

\section{Conclusion}

The impact of the Covid-19 pandemic has made changes to physical activity habits in elementary school children. Maintaining a diet with a balanced nutritional intake and regular physical activity is important in an effort to maintain endurance in the midst of a pandemic. Physical activity, nutrition in elementary school children is very necessary to maintain the body's immunity

\section{Acknowledgement}

Our gratitude gives to elementary school students N 1 Kaliuntu who have been willing to be made a respondent. To all parties who helped carry out the research.

\section{References}

[1] P. Polero et al., "Physical activity recommendations during COVID-19: Narrative review," Int. J. Environ. Res. Public Health, vol. 18, no. 1, pp. 1-24, 2021, doi: 10.3390/ijerph18010065.

[2] F. Naja and R. Hamadeh, "Nutrition amid the COVID-19 pandemic: a multi-level framework for action," Eur. J. Clin. Nutr., vol. 74, no. 8, pp. 1117-1121, 2020, doi: 10.1038/s41430-020-0634-3.

[3] J. A. Woods et al., "The COVID-19 pandemic and physical activity," Sport. Med. Heal. Sci., vol. 2, no. 2, pp. 55-64, 2020, doi: 10.1016/j.smhs.2020.05.006.

[4] S. Mishra and M. Patel, "Role of Nutrition on Immune System During Covid-19 Pandemic," J. Food Nutr. Heal., vol. 3, no. 2, pp. 1-6, 2020.

[5] Z. Tavakol et al., "Relationship between physical activity, healthy lifestyle and COVID-19 disease severity; a cross-sectional study," J. Public Heal., 2021, doi: 10.1007/s10389-020-01468-9.

[6] A. V. Mattioli, S. Sciomer, C. Cocchi, S. Maffei, and S. Gallina, "Quarantine during COVID-19 outbreak: Changes in diet and physical activity increase the risk of cardiovascular disease," Nutr. Metab. Cardiovasc. Dis., vol. 30, no. 9, pp. 1409-1417, 2020, doi: 10.1016/j.numecd.2020.05.020.

[7] G. V. Grivas, "Journal of Sports and Exercise Medicine," J. Sport. Exerc. Med., vol. 1, no. 1, pp. 1-2, 2018, doi: 10.14302/issn.2694-2283.jsem-18-1924.

[8] H. J. B. Jan Mohamed and T. E. Siong, "Nutrition, immunity and COVID-19,” Malays. J. Nutr., vol. 26, no. 1, pp. i-ii, 2020, doi: 10.31246/MJN-EDITORIAL-26-1.

[9] M. Sutaria, G. Keny, and S. A. Pratinidhi, "COVID-19 and its effect on nutrition," Int. J. Community Med. Public Heal., vol. 7, no. 10, p. 4112, 2020, doi: 10.18203/2394-6040.ijcmph20204385.

[10] T. M. Matsungo and P. Chopera, "Effect of the COVID-19-induced lockdown on nutrition, health and lifestyle patterns among adults in Zimbabwe," BMJ Nutr. Prev. Heal., vol. 3, no. 2, pp. 205-212, 2020, doi: 10.1136/bmjnph-2020-000124.

[11] W. K. Abdelbasset, "Stay Home: Role of physical exercise training in elderly individuals' ability to face the covid-19 infection," J. Immunol. Res., vol. 2020, 2020, doi: 10.1155/2020/8375096.

[12] H. Guan et al., "Promoting healthy movement behaviours among children during the COVID-19 pandemic," Lancet Child Adolesc. Heal., vol. 4, no. 6, pp. 416-418, 2020, doi: 10.1016/S2352-4642(20)30131-0.

[13] F. R. Scartoni et al., "Physical Exercise and Immune System in the Elderly: Implications and Importance in COVID-19 Pandemic Period," Front. Psychol., vol. 11, no. November, 2020, doi: 10.3389/fpsyg.2020.593903. 